\title{
Belphégor
}

\section{Philippe Clermont, Arnaud Huftier, Jean-Michel Pottier, Un seul monde. Relectures de Rosny aîné}

\section{François-Xavier Eygun}

\section{(2) OpenEdition}

1 Journals

\section{Édition électronique}

URL : http://journals.openedition.org/belphegor/403

DOI : 10.4000/belphegor.403

ISSN : 1499-7185

Éditeur

LPCM

\section{Édition imprimée}

Date de publication : 10 janvier 2011

\section{Référence électronique}

François-Xavier Eygun, « Philippe Clermont, Arnaud Huftier, Jean-Michel Pottier, Un seul monde. Relectures de Rosny aîné », Belphégor [En ligne], 10-3 | 2011, mis en ligne le 10 janvier 2013, consulté le 22 septembre 2020. URL : http://journals.openedition.org/belphegor/403 ; DOI : https://doi.org/ 10.4000/belphegor.403

Ce document a été généré automatiquement le 22 septembre 2020

\section{(c) (7) $\odot$}

Belphégor est mis à disposition selon les termes de la Licence Creative Commons Attribution - Pas d'Utilisation Commerciale - Pas de Modification 4.0 International. 


\title{
Philippe Clermont, Arnaud Huftier, Jean-Michel Pottier, Un seul monde. Relectures de Rosny aîné
}

\author{
François-Xavier Eygun
}

\section{RÉFÉRENCE}

Philippe Clermont, Arnaud Huftier, Jean-Michel Pottier, Un seul monde. Relectures de Rosny aîné, Presses Universitaires de Valenciennes, 350p., ISBN : 978-2-905725-37-0

1 Qui n'a pas entendu le nom de Rosny ? Le film, La guerre du feu l'a rendu populaire, mais cela s'arrête souvent là. Grâce à cet essai, le lecteur découvrira les multiples facettes de cet auteur qui fut non seulement apprécié et lu mais aussi qui aura joué un rôle non négligeable dans le monde littéraire français de la fin du $\mathrm{XIX}^{\mathrm{e}}$ au début $\mathrm{du} \mathrm{xx}^{\mathrm{e}}$ siècle.

Il était grand temps de sortir Rosny aîné (1856-1940) d'un long purgatoire et ce livre un peu hybride, le fait de façon intéressante et constructive puisqu'il propose des contributions de différents spécialistes qui sont comme autant de relectures de cet auteur et où l'on retrouvera des informations biographiques, bibliographiques, d'histoire et d'analyse littéraire.

On découvre à la lecture de cet ouvrage que l'œuvre de Rosny fut abondante puisqu'elle se compose de plus de cent cinquante romans, de nombreux contes et chroniques qui couvrent autant la préhistoire que l'histoire, la philosophie, les mémoires et les souvenirs de la vie littéraire, le merveilleux scientifique pour ne nommer que quelques uns des multiples intérêts de cet auteur prolifique.

Cet ouvrage, Un seul monde. Relectures de Rosny aîné, est constitué de trois moments. Le premier est intitulé « Les mondes connus » et permet de replacer Rosny dans l'histoire littéraire - le naturalisme, les milieux anarchistes et socialistes entre autres - grâce aux contributions d'Alain Pagès, de Jean-Michel Pottier, de Vittorio Frigerio, d'Éric Lysoe, de Daniel Aranda et de Jean-Pierre Picot. 
5 Le deuxième moment ou la découverte des "nouveaux mondes ", étudie et analyse la perspective du merveilleux scientifique qui reste l'aspect le plus connu de l'œuvre de Rosny aîné. Les contributions d'Arnaud Huftier, de Philippe Clermont, de François Laforge, de Roberta de Felici, de Daniel Couegnas et de François Grande contribuent à mieux apprécier sinon à découvrir l'évocation des mondes du passé et ceux du futur qui constituent l'originalité de l'oeuvre de Rosny aîné.

6 Finalement un troisième volet ou moment de cet ouvrage mi-critique, mi biographique est constitué de l'élément bibliographique qui détaille le fonds Rosny aîné, légué à la ville de Bayeux par Robert Borel-Rosny petit-fils de l'auteur et à qui Jean-Michel Pottier rend hommage et que Sylvie Lemagnen présente dans son introduction.

7 Ce recueil d'études a le grand avantage de faire découvrir le personnage et l'œuvre de Rosny aîné dans son contexte historique et culturel. Il est de plus, agrémenté de photos de Rosny et de documents d'époque. Les études vont de l'analyse littéraire pointue aux souvenirs littéraires de Rosny aîné et se concluent sur une étude sur le fonds Rosny légué à la médiathèque de Bayeux. Cela donne envie de lire plus de cet auteur et en cela cet ouvrage est une réussite. 